\title{
APARTAMENTOS DUPLEX:
}

MODERNIDADE, USOS E CONSERVAÇÃO

SABRINA STUDART FONTENELE COSTA UNIVERSIDADE ESTADUAL DE CAMPINAS, CAMPINAS, SÃO PAULO, BRASIL Arquiteta pela Universidade Federal do Ceará (2000). Mestre e doutora pela FAU-USP. Desenvolve pesquisa de pós-doutorado no Instituto de Filosofia, Ciências Humanas da Unicamp com apoio da Fapesp com o tema modos de morar nas metrópoles. Autora do livro Edifícios modernos e traçado urbano no Centro de São Paulo (1938-1960) (Annablume, 2015).

E-mail: ssfc@unicamp.br

DOI

http://dx.doi.org/10.11606/issn.1980-4466.v0iesp22p115-137 


\section{APARTAMENTOS DUPLEX: MODERNIDADE, USOS E CONSERVAÇÃO \\ SABRINA STUDART FONTENELE COSTA}

\section{RESUMO}

Este trabalho pretende discutir a preservação dos apartamentos duplex modernos na cidade de São Paulo. Símbolos de um modo de viver moderno, esses espaços anunciavam as novas possibilidades de desenho e de organização doméstica. Os primeiros exemplares foram projetados como uma maneira de arranjar espaços habitacionais com áreas pequenas, sua organização em níveis permitia a separação entre setores de atividades da casa e economizava paradas de elevador. O conjunto habitacional soviético Narkonfim (1928-1929) foi pioneiro, mas foi a Unidade de Habitação de Marselha (1945-1952) que ganhou destaque internacional. Os dois conjuntos habitacionais buscavam suprir a demanda habitacional das grandes metrópoles. No Brasil, as primeiras iniciativas associadas aos apartamentos dúplex vinculavam-se às iniciativas governamentais de produção de moradia. No entanto, outros empreendimentos modernos com essa tipologia foram propostos na cidade de São Paulo, com áreas maiores, em localizações privilegiadas, voltados para um público de alto poder aquisitivo. A análise aqui proposta buscará apresentar as transformações físicas pelas quais passaram alguns exemplares desses apartamentos para compreender as adaptações aos hábitos, rotinas e modos de vida dos proprietários e moradores no contexto atual.

\section{PALAVRAS-CHAVE}

Domesticidade. Arquitetura moderna. Patrimônio cultural. 


\section{DUPLEX APARTMENTS: MODERNITY, USES AND CONSERVATION \\ SABRINA STUDART FONTENELE COSTA}

\section{ABSTRACT}

This paper aims to discuss the preservation of the modern duplex apartments in the city of Sao Paulo. As symbols of a modern way of living, these spaces announced the new design and domestic organization possibilities. The first examples of duplex apartments were designed as a way of arranging living spaces in small areas, since their setup on levels allowed separating the different house activities and saving elevator stops. Having their concept based on the Soviet Housing Narkonfim (1928-1929) and gaining international prominence with the French architectural complex Marseilles Housing Unit (1945-1952), the duplex apartment housings were designed to meet the housing demand in large cities. In Brazil, the government pioneered housing initiatives associated with this typology. However, other similar modern developments, but with larger areas and in prime locations were proposed in São Paulo for the high-income population. The analysis seeks to present the physical transformations in some of these apartments in order to understand the adjustments to the habits, routines and ways of life of the owners and residents in the current context.

KEYWORDS

Domesticity. Modern architecture. Cultural heritage. 


\section{INTRODUÇÃO}

Este artigo se propõe a analisar os projetos, a construção, os usos e a conservação de alguns conjuntos habitacionais que se utilizaram da organização dos apartamentos em níveis para distribuir atividades domésticas e propor novas formas de domesticidade'. Para tanto, são utilizados três estudos de caso da cidade de São Paulo, foram necessárias comparações com algumas experiências pioneiras internacionais. Se hoje a capital paulista tem uma imagem associada aos arranha-céus modernos que se distribuem por toda a cidade, ainda nas primeiras décadas do século XX existia uma forte resistência às habitações coletivas. $O$ interesse pelos conjuntos habitacionais na cidade de São Paulo ocorreu de maneira gradual, como explica o historiador Paulo César Garcez Marins:

A resistência à moradia coletiva, discriminada pelos discursos oficiais como sinônimo de todas as desgraças sanitárias presentes nas capitais brasileiras desde o Império, foi aos poucos arrefecendo diante da novidade constituída pelos apartamentos, inicialmente dirigidos aos segmentos mais abastados das grandes cidades. O receio de decair socialmente, advindo do desprezo para com as coabitações, foi vencido com a adoção

1. Agradeço à Marina Leonardi e Flavia Brito do Nascimento pelas fotos da Unidade de Marselha, cedidas para este artigo e, especialmente à Gabriela Piccinini pela elaboração dos desenhos dos conjuntos e apartamentos analisados. 
de acabamentos custosos utilizados nos revestimentos externos e nas áreas internas de circulação dos edifícios. (MARINS, 1998, p. 187)

Importante lembrar que o momento de implantação dos conjuntos habitacionais aqui estudados é justamente o de fortes transformações físicas dos espaços urbanos e da verticalização da cidade a partir do Centro. O entorno da Praça da República - nas proximidades de onde se implantam alguns dos exemplares aqui estudados - foi onde ocorreram as intervenções urbanas mais fortes nesse período, tendo sido foco direto de diversos investimentos públicos (a exemplo da abertura e alargamento das avenidas na gestão do prefeito Prestes Maia), assim como empreendimentos imobiliários. Neste período, as casas e chácaras existentes na região foram substituídas por arranha-céus que rompiam a escala horizontal da cidade e apresentavam propostas espaciais modernas.

Além das transformações físicas e urbanas da metrópole, era percebível uma mudança no modo de vida urbano presente nas mais diversas atividades que ocorriam por São Paulo: novos programas, novos hábitos, novos circuitos.

Era nas cidades, as quais trocavam sua aparência paroquial por uma atmosfera cosmopolita e metropolitana, que se desenrolavam as mudanças mais visíveis. Através de um processo diagnosticado por vários críticos temerosos como imperfeito e desorganizado, a nova paisagem urbana, embora ainda guardasse muito da tradição, era povoada por uma população nova e heterogênea, composta de imigrantes, de egressos da escravidão e de representantes das elites que se mudavam do campo para as cidades. (MALUF; MOTT, 1999, p. 371)

Neste sentido, abordar as propostas de domesticidade nos conjuntos habitacionais e apartamentos duplex modernos está diretamente relacionado à tentativa de compreender em que medida os arranjos propostos modificam a dinâmica nas famílias, assim como compreender que tipos de objetos, mobiliários e disposições são incentivados nessas habitações.

\section{APARTAMENTOS MODERNOS DUPLEX NO BRASIL}

Este artigo trata de algumas iniciativas realizadas por arquitetos vinculados ao movimento moderno e com uma tipologia habitacional que foi proposta no século XX: os apartamentos duplex. Essa organização espacial surge 
inicialmente como resposta a um modo de morar funcional, a partir de plantas eficientes e construções econômicas. A organização em níveis dos apartamentos duplex permite a separação entre setores de atividades da casa (áreas sociais e íntimas) e realiza a economia de paradas de elevador.

No Brasil, iniciativas pioneiras de habitação moderna estiveram associadas aos apartamentos duplex. Em São Paulo, essa tipologia se consolidou a partir da década de 1940, mas já apresentava alguns exemplares ainda na década de 1930. Destacam-se empreendimentos como o Edifício Anchieta (MMM Roberto, 1941), Pedregulho (Affonso Reidy, 1950), Guapira e Hicatu, no Conjunto Residencial Ana Rosa (Eduardo Kneese de Mello, 1952), em grande parte fruto das iniciativas governamentais de produção de moradia. Essas iniciativas vinculavam-se diretamente aos Institutos de Aposentadoria e Pensões ${ }^{2}$ (IAP), que foram responsáveis por diversos empreendimentos imobiliários nas cidades brasileiras.

Na área central de São Paulo, por iniciativa do Instituto de Aposentadoria e Pensões dos Industriários (IAPI), foi construído o conjunto Japurá - oficialmente denominado Conjunto Residencial Armando de Arruda Pereira. Localizado na região da Bela Vista, substituiu o antigo cortiço conhecido como "Navio Parado", constituído por unidades com dois pavimentos e uma longa varanda de circulação (BONDUKI; KHOURY, 2014). O Japurá, projetado pelo arquiteto Eduardo Kneese de Mello, marcou a paisagem em uma região encortiçada que sofreu ações higienistas para a construção do Perímetro de Irradiação, durante a gestão do prefeito Prestes Maia.

Nesse complexo habitacional comporto por duas lâminas de habitação, enquanto a primeira torre, mais baixa, é formada por quitinetes destinadas a jovens solteiros (inclusive com entrada independente, para não se misturarem com as famílias que abrigavam a grande torre) e ao comércio, a grande torre tem 14 pavimentos e abriga 288 unidades habitacionais duplex que propiciam a divisão entre espaços íntimos e os destinados a usos sociais, e permite grandes economias na construção (REGINO; PERRONE, 2009, p. 77).

2. Segundo Nabil Bonduki, "organizados de forma corporativa, por categoria profissional, os IAPs tinham por objetivo primeiro garantir aposentadorias e pensões à previdência social, seguindo atendimento à saúde vindo por último às inversões imobiliárias, em que estava incluída a possibilidade de produzir e financiar moradias para os associados dos institutos" (BONDUKI, 2014, p. 46). 
Os apartamentos duplex têm suas áreas sociais distribuídas nos andares inferiores (sala, cozinha, despensa e hall da escada), enquanto os andares superiores abrigam dois quartos e banheiro. Um problema levantado na concepção de áreas econômicas e rentáveis foi a necessidade de se instalar um tanque no banheiro, para que funcionasse como lavanderia.

FIGURA 1

Plantas dos apartamentos duplex do Edifício Japurá. Legenda: vermelho - áreas sociais; azul - áreas íntimas; amarelo serviços. Desenhos:

Sabrina Costa e Gabriela Piccinini.

As mulheres nas representações do

Conjunto Japurá Fonte: MELLO, E. K. Apartamentos industriários. Revista Acrópole, n. 119 p. 287, mar. 1948.

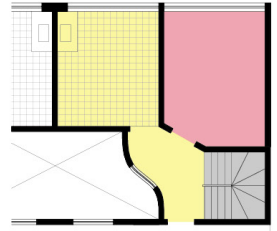

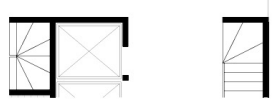

Pav. Inferior (entrada)

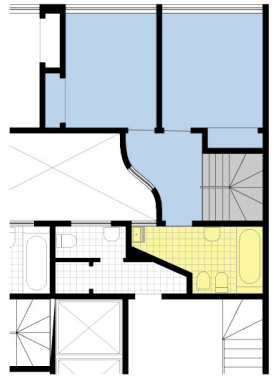

Pav. Superior
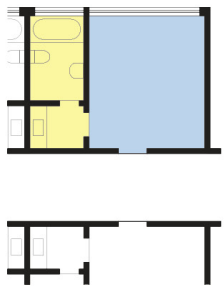

Kitnet

ED. JAPURÁ

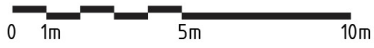

\section{A PARTAMENTOS PARA INDUSTRIARIOS}

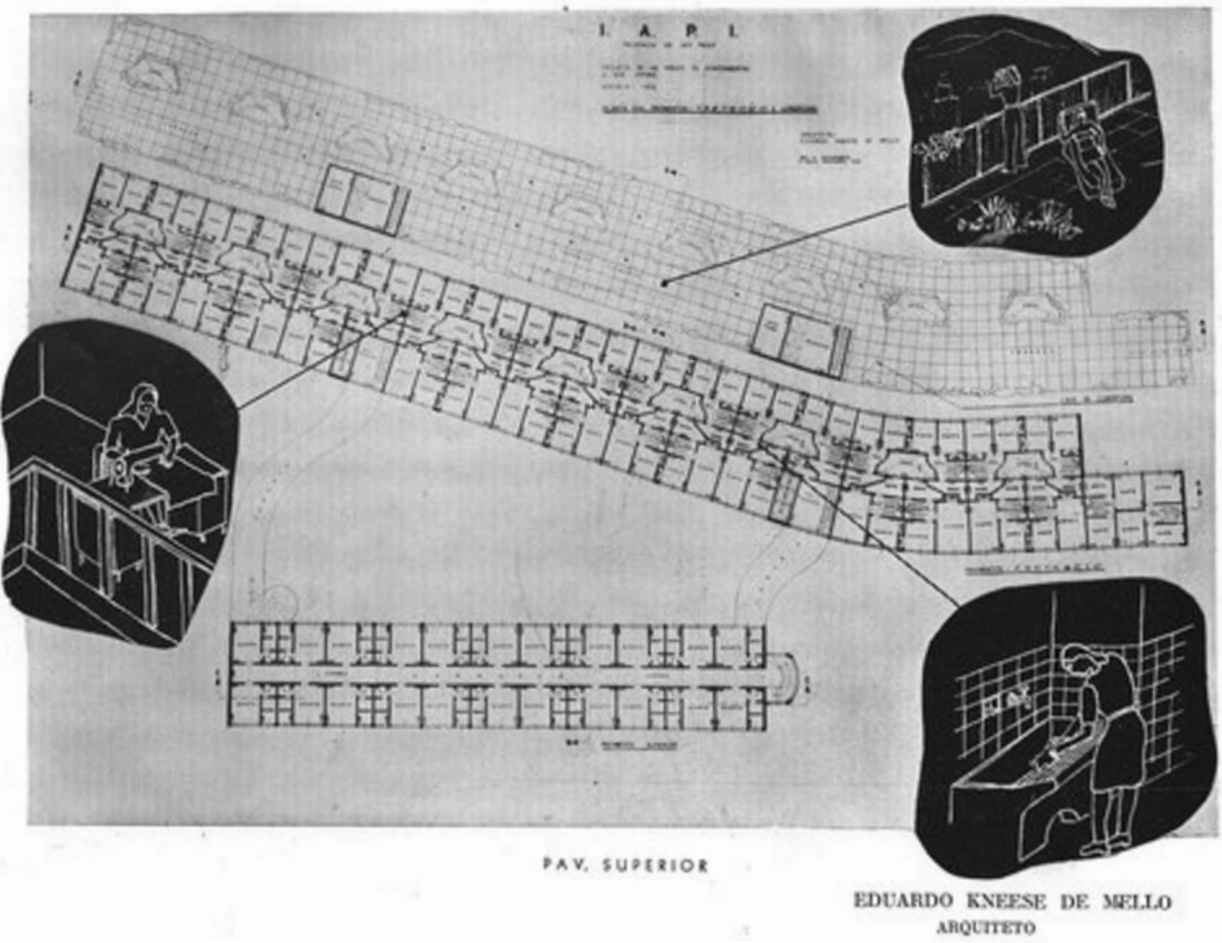


Alguns desenhos demostram a ideia do arquiteto para a vida no conjunto habitacional a partir de ilustrações que representam seus moradores em diversas atividades e em vários espaços do complexo: mulheres lavando, cozinhando, costurando ou cuidando de sua beleza. No entanto, outros empreendimentos modernos com a tipologia dos duplex foram propostos na cidade de São Paulo, com áreas maiores, em localizações privilegiadas e voltadas para um público de poder aquisitivo maior. Por exemplo, os edifícios Eiffel (1951) e Esther (1937), ambos na região central da cidade.

Associando a ideia de modernidade, destaca-se o Edifício Esther com vários andares em uma das regiões mais valorizadas de São Paulo, nos arredores da Praça da República, empreendimento levado à frente pela família Nogueira. No início dos anos 1930, sua iniciativa associava ousadia, visão empresarial e modernidade. A preocupação dos arquitetos com as questões funcionais e construtivas trouxe soluções inovadoras ao edifício: planta livre, espaços flexíveis, janelas corridas nos andares de escritório e diferentes recursos de proteção à insolação nas diversas fachadas.

Uma primeira aproximação com o tema dos duplex apresenta-se no livro de Fernando Atique sobre o Edifício Esther, que apresenta a disposição espacial dos apartamentos que se localizavam entre o $9^{\circ}$ e $10^{\circ}$ pavimentos.

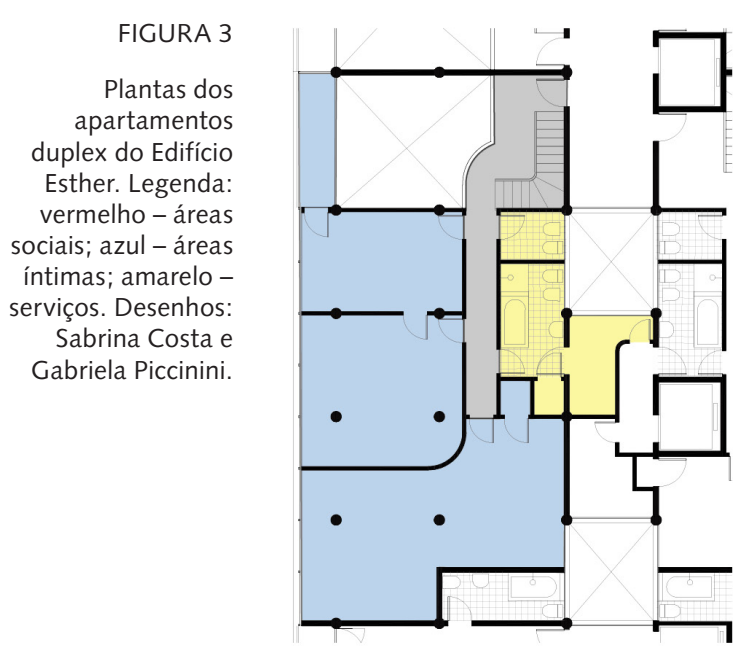

Pav. Superior

ED. ESTHER - TIPOLOGIA DUPLEX

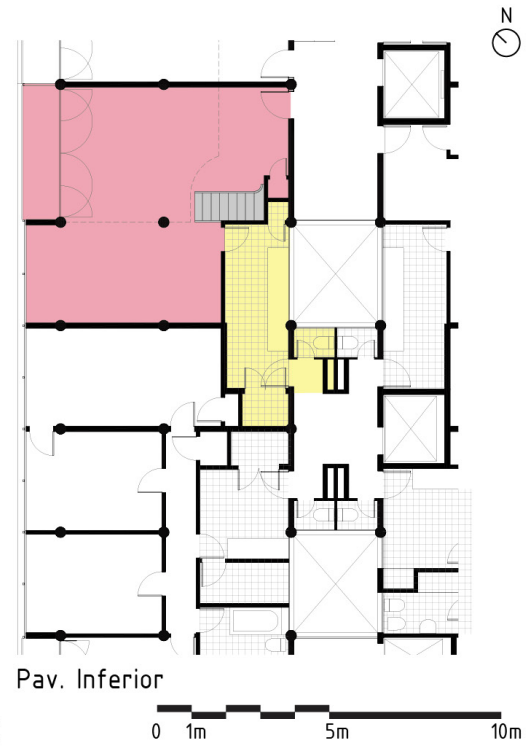


Os duplex - denominados pelo arquiteto Vital Brazil como "apartamentos duplos de luxo" (ATIQUE, 2013, p. 201) - eram compostos por uma sala de estar com pé direito duplo, vestíbulo, escada, sala de jantar, cozinha, despensa e dependências de empregados. O próprio programa já indica que aqui a análise é muito diferente daquela apresentada quando se trata do Japurá, onde as áreas mínimas dos apartamentos sugeriam um cuidado com a funcionalidade e exiguidade dos espaços domésticos.

Fotos da ocupação dos apartamentos pelos primeiros proprietários poderiam ilustrar os modos de ocupação dos cômodos e sua organização espacial. No entanto, as imagens mais antigas dos apartamentos que foram encontradas são as publicadas no catálogo do Brazil Builds que apresentam os apartamentos vazios, sem ocupação. No croqui do arquiteto chama a atenção uma pessoa no mezanino da sala de estar que observa o apartamento ainda vazio. Nenhuma mobília, além de um trilho com uma cortina que apresenta a possiblidade de separação entre ambientes diversos (recurso comum entre os arquitetos modernos), ressaltando a ideia da planta livre. A janela em fita apresenta a cidade ao fundo, demostrando o lugar onde se implantava um centro urbano que se verticalizava. Atualmente, apenas um exemplar preserva o pé-direito duplo da sala, pois a maioria dos proprietários optou por fechar o vão com uma laje para aumentar a área disponível.

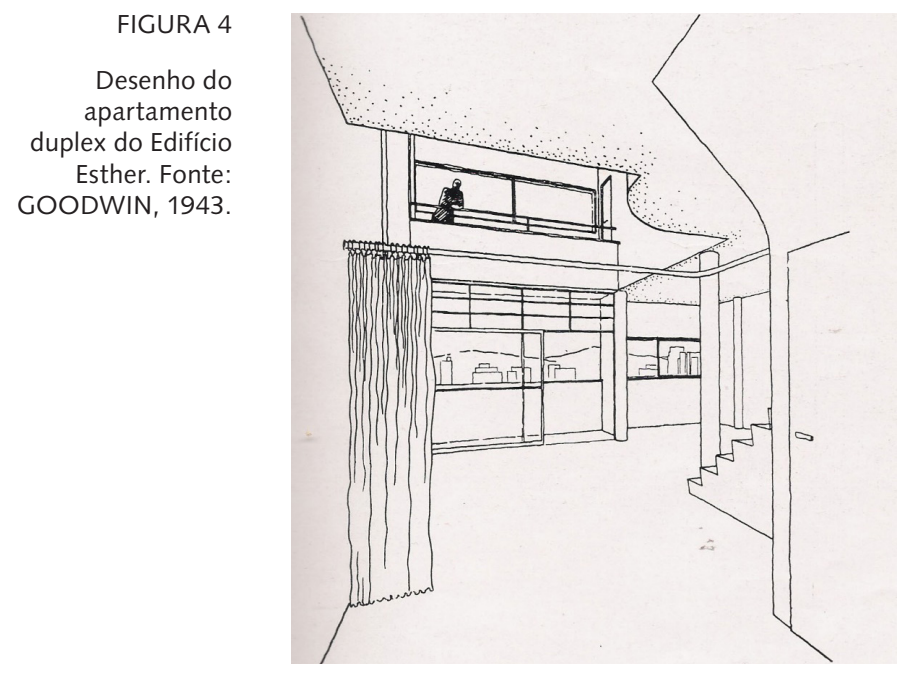


O imóvel, tombado em 1998 pelo Condephaat, apresenta entre seus primeiros moradores o casal Emiliano Di Cavalcanti e Noêmia Mourão. De volta depois de uma temporada em Paris, o casal de artistas passou a morar no duplex do Edifício Esther, onde realizavam festas e encontros para os amigos e intelectuais. O grande apartamento, no símbolo da modernização da cidade, parece ter área suficiente para sociabilizar e para abrigar a vida doméstica e sua intensa produção artística. A modernidade no Edifício Esther fica ainda mais evidente quando se analisa o programa implantado em seus pavimentos: lojas comerciais no pavimento térreo, salas de escritório e consultórios médicos e odontológicos, apartamentos simples e os duplex. Ou seja, o morador teria à sua disposição, em um único edifício, diversos serviços que possibilitariam agilidade e eficiência na agitada vida metropolitana.

Entrevistas realizadas com moradores atuais dos apartamentos revelam alguns pontos em comum de seu interesse pelo edifício: localização privilegiada, funcionamento por 24 horas, vista da Praça da República. Hoje, dois dos apartamentos duplex permanecem como residência, enquanto um deles se converteu em escritório de advocacia e outro foi alugado por um coletivo de artistas para um espaço de trabalho e exposição. A advogada Márcia Cristina Olmos, antiga síndica do prédio e proprietária de um apartamento no terraço, sintetiza em uma frase o interesse original pelo edifício: "esse prédio é o símbolo de São Paulo: total diversidade”. A diversidade é expressa nos usos variados que ocorrem nos pavimentos do edifício: escritórios, cabelereiros, restaurantes, casa noturna e habitação. Além disso, uma mesquita funcionou em um dos apartamentos duplex entre os anos de 2004 e 2012, recebendo mulçumanos de origem africana da região central da cidade.

Algumas tentativas de restauração do imóvel foram realizadas nas últimas décadas, mas os avanços não foram suficientes para garantir a integridade do conjunto. A partir da Praça da República é possível perceber no segundo andar do complexo que parte da janela em fita foi fechada com alvenaria. Além disso, são perceptíveis os problemas de conservação do conjunto arquitetônico: infiltração, desplacamento da argamassa da fachada, entre outros. Entre as novas dinâmicas e usos do edifício, destaca-se a reformulação de um dos apartamentos da cobertura para a instalação de um restaurante por um renomado chefe de cozinha. 


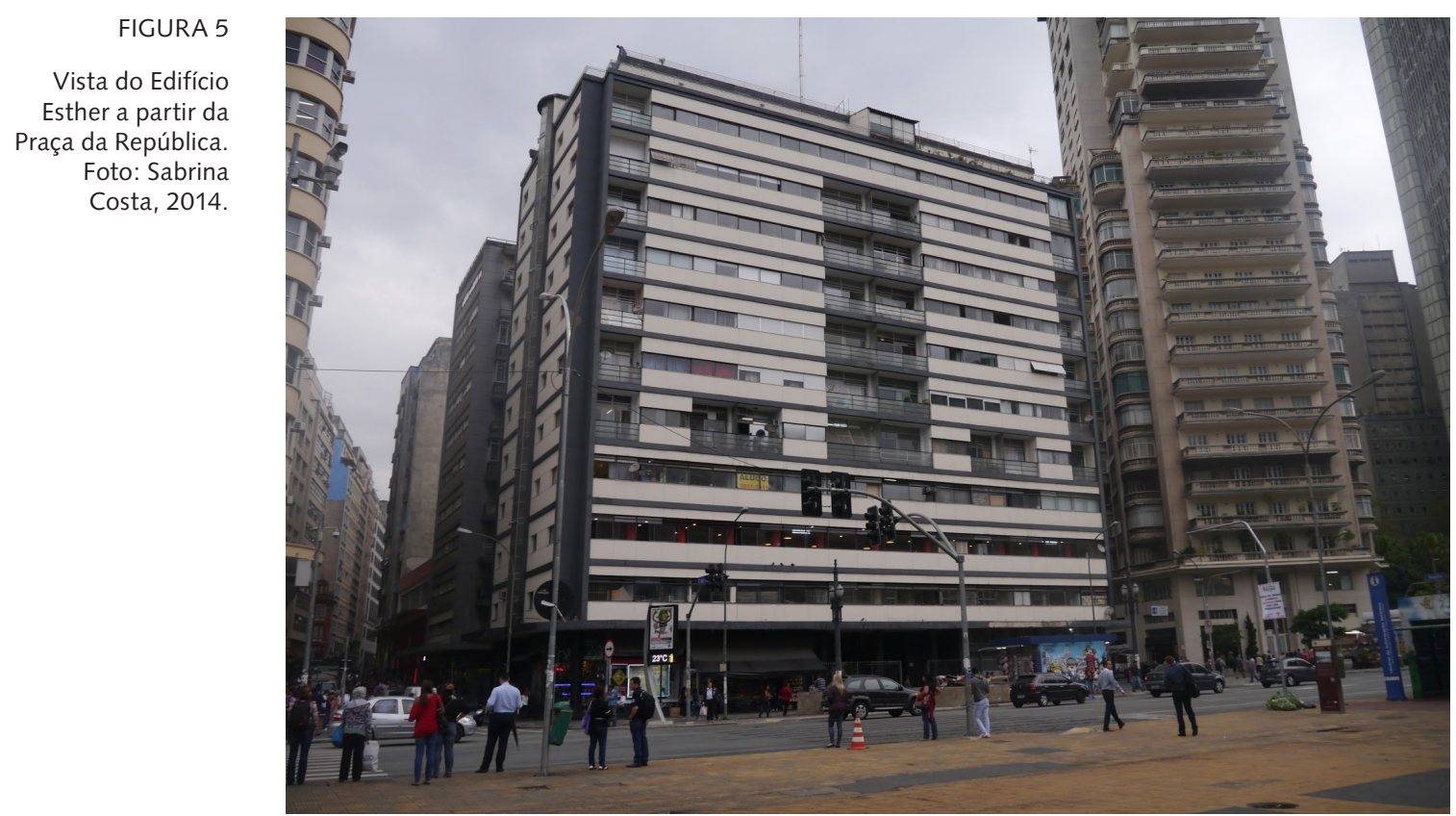

\section{EXPERIÊNCIAS PIONEIRAS}

Um levantamento histórico sobre os apartamentos duplex nos conjuntos habitacionais modernos que está diretamente relacionada às experiências habitacionais soviéticas, ainda na década de 1920. A abolição da propriedade privada e a nacionalização das terras possibilitaram avançar no problema da habitação social. Os ambiciosos programas de habitação deram oportunidade aos arquitetos de planejar novas estruturas baseadas nas mudanças da estrutura familiar que afetavam diretamente o futuro do desenho da casa. As rotinas das famílias de trabalhadores, assim como a educação das crianças, poderiam ser coletivizadas. Assim, os espaços de vida doméstica são mínimos para incentivo à vida comunitária. "O conjunto das tarefas domésticas também é coletivizado da mesma forma que a preparação das refeições; mas o modo de vida das comunidades não concerne apenas à vida doméstica" (KOPP, 1990, p. 89).

O Narkonfim (1928-1929), projetado pelo arquiteto russo Moisiei Guinzburg, coordenador do Comitê de Construções Estatais, foi construído para os funcionários do Ministério das Finanças Nacionais na região central de Moscou. Ali, células habitacionais de 27 a 30 metros quadrados eram 
organizadas em dois pavimentos associados a equipamentos coletivos: cozinha e sala de jantar coletivas, lavanderia, serviço de limpeza dos alojamentos, jardim de infância, ginásio esportivo, biblioteca e um terraço de uso coletivo. Assim, propunha efetivamente uma convivência intensa entre seus habitantes.

A tentativa de 'reconstruir' a vida cotidiana por meio de coletivismo conduziu à realização, na segunda metade da década de 1920, de experiências em grande escala que incluíam instalações compartilhadas para a preparação de refeições, com o que se pretendia compensar a pequenez das unidades habitacionais (COHEN, 2014, p. 170).

FIGURA 6

Plantas dos apartamentos duplex tipo $\mathrm{F}$ e tipo $\mathrm{K}$ no Narkomfin. Legenda: vermelho - áreas sociais; azul - áreas íntimas; amarelo serviços. Desenhos: Sabrina Costa e Gabriela Piccinini.

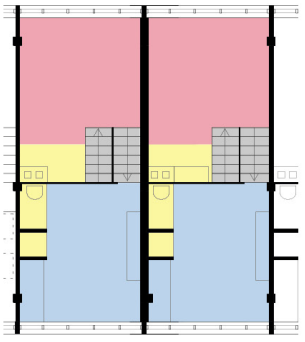

Pav. Superior

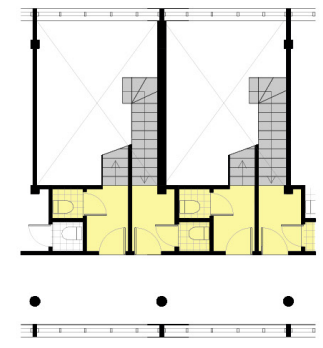

Entrada

NARKOMFIN - TIPOLOGIA F

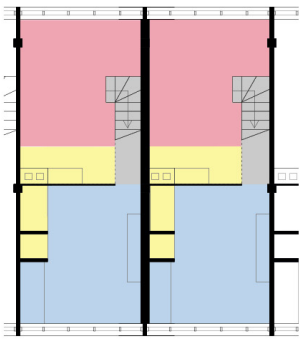

Pav. Inferior
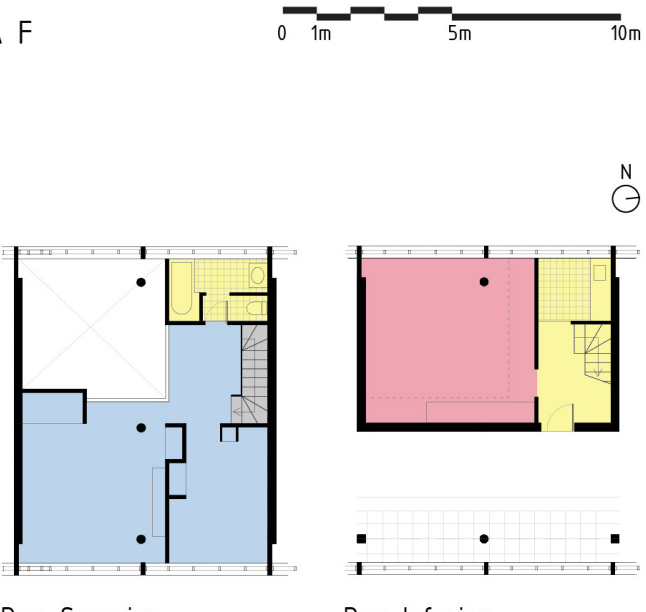

Pav. Superior

Pav. Inferior

NARKOMFIN - TIPOLOGIA K

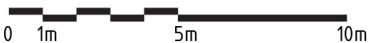


Por conta dos baixos aluguéis, o edifício Narkomfin passou a ser ocupado por artistas, o que garantiu uma forte diversidade entre os moradores, mas passou por um estado de deterioração física nas últimas décadas, tendo sido incluído na lista do World Monuments Watch ${ }^{3}$ nos anos 2002, 2004, e 2006. Em termos físicos, é possível perceber que sua fachada está se desintegrando, existem vazamentos nas varandas e desplacamento dos revestimentos. Há pelo menos cinco anos, reportagens internacionais denunciam a forte pressão que os moradores passaram a sofrer desde que um empresário russo comprou várias unidades e se interessou por "revitalizar" o complexo habitacional (RANN, 2014). Localizado em uma área central, adjacente às áreas de interesse para a especulação imobiliária, o empreendimento ganhou visibilidade e destaque após anos de abandono. Assim, a ideia do empresário - que atualmente é dono de todos os apartamentos, com exceção de cinco unidades - seria transformá-lo em um hotel que, em princípio, tentaria manter as características originais do empreendimento, mas atenderia outro público. Uma série de reportagens alerta para o perigo de expulsão dos moradores que há décadas vivem nos edifícios pelas altas dos aluguéis. Dentro de uma lógica econômica completamente diferente da realizada no momento de sua proposta e construção, questiona-se se a ocupação do conjunto - espaço marcado historicamente pelas atividades coletivas - não aponta para uma tentativa de apagar o passado soviético do edifício.

O cotidiano de alguns apartamentos do conjunto arquitetônico russo pode ser vislumbrado a partir de um documentário. O sítio eletrônico $<$ http://www. narkomfin.net> apresenta a relação entre espaços os construídos e seus moradores a partir de detalhes fotografados e levantados pelos seus realizadores e oferece verdadeiro passeio pelo conjunto. Em meio a apartamentos cuja passagem do tempo se mostra de maneira explícita, é possível verificar a individualização de cada célula habitacional. A análise dos apartamentos pelo site demonstra que muitos moradores utilizam seus interiores como área de moradia e trabalho, especialmente os designers e artistas que personalizam seus espaços interiores. Atualmente, o futuro desses moradores é incerto, assim como da conservação do edifício.

3. World Monuments Fund é uma organização privada sem fins lucrativos fundada em 1965 que patrocina um programa contínuo para a conservação do patrimônio cultural em todo o mundo. Desde 1995, a WMF tem um programa que procura identificar sítios do patrimônio cultural em perigo e dar apoio técnico e financeiro direto para a sua conservação. Mais informações em $<$ https://www.wmf.org $>$. 
Enquanto o Narkomfin colocou-se como uma possibilidade para os funcionários públicos de um Estado que sofria com o déficit habitacional, no contexto pós-guerra europeu a Unidade de Habitação em Marselha (1946-1952) foi desenvolvida por Le Corbusier sob influência da experiência soviética como uma possibilidade de habitação em grande escala. O edifício agrega 1.600 pessoas em seus 337 apartamentos em uma lâmina de 100 metros de comprimento por 30 metros de largura, repetida em 15 andares. Os apartamentos duplex se alongam de leste a oeste e são acessados a cada três andares por corredores de acesso (COHEN, 2013). Os apartamentos duplex têm plantas variadas, mas um modelo tipo se repete em mais de 200 unidades (que tinham em geral $98 \mathrm{~m}^{2}$ ). O acesso é pela região próxima da cozinha e o morador pode descer ou subir um lance de escadas para chegar aos dormitórios.

A concepção da cozinha dos apartamentos da Unidade de Marselha teve a colaboração de Charlotte Perriand ${ }^{4}$, que foi fundamental para propor arranjos modernos em uma cozinha de pequenas dimensões. Em uma área de $4,8 \mathrm{~m}^{2}$, implantava-se uma cozinha em formato de " $U$ " que colocava à disposição das famílias os equipamentos necessários para o armazenamento e preparo dos alimentos e limpeza dos utensílios e louças.

Assim como no conjunto soviético, as mais diversas atividades urbanas ocorriam no próprio edifício: comércio, serviço, recreação, educação, distribuídas entre o terraço e outros andares. $\mathrm{O} 17^{\circ}$ andar abrigou uma creche, enquanto o terraço-jardim abrigou equipamentos esportivos e recreativos e uma piscina rasa. O edifício propunha novos modos de morar onde diversas atividades urbanas eram possíveis em uma mesma construção. Segundo Jean Louis-Cohen:

Here he combined his urban and domestic theories: these large-scale apartment were intended to provide not only the basic needs of the inhabitants (shops, school, gymnasium, running track) inside each block, but also a private domestic space on which every dweller would be assured perfect quiet and a splendid view ${ }^{5}$ (COHEN; BENTON, 2008, p. 365).

4. Importante ressaltar que Charlotte Perriand projetou quase todo o mobiliário do edifício. 5. Aqui ele combinou suas teorias urbanas e domésticas: esses blocos de larga escala de apartamentos foram destinados a fornecer não só as necessidades básicas dos habitantes (lojas, escola, ginásio, pista de corrida) dentro de cada bloco, mas também um espaço doméstico privado no qual a cada morador estaria assegurada perfeita calma e uma vista esplêndida (tradução livre da autora). 

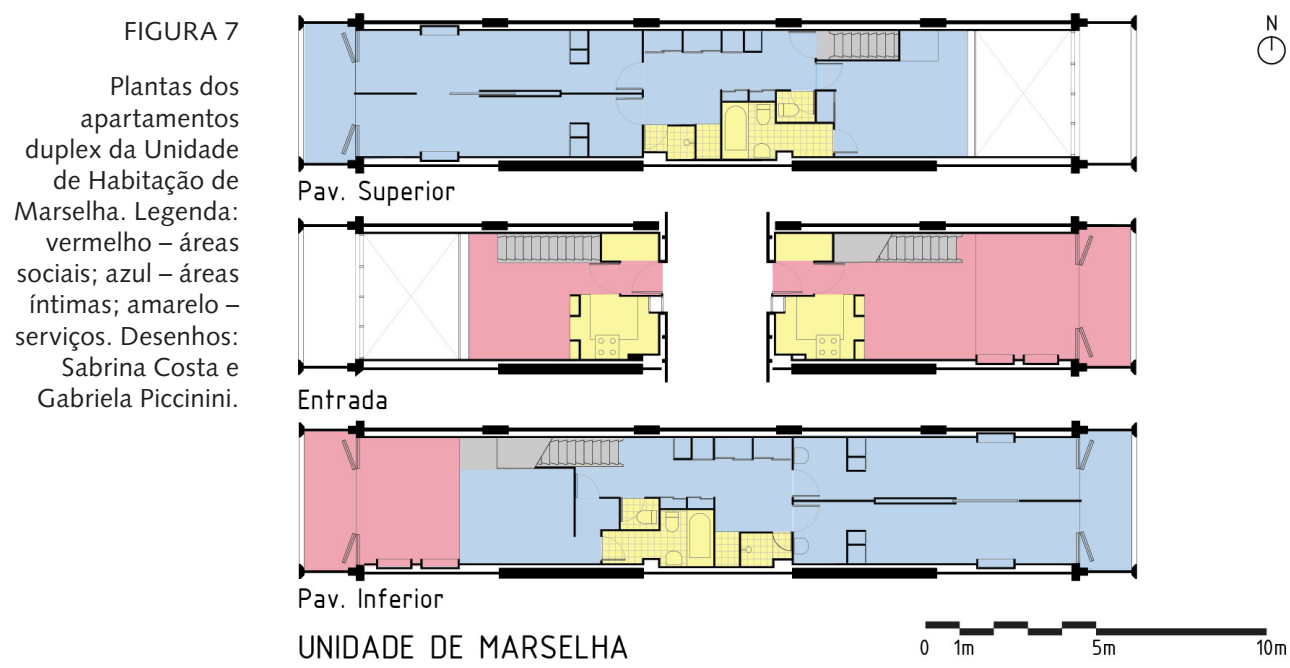

A Unidade de Habitação de Marselha integrou o inventário da obra de Le Corbusier, feito pelo governo francês no início dos anos 1960, como parte do processo mais geral de valoração da obra do mestre franco-suíço relacionado à tentativa de recuperação da Villa Savoye. O complexo arquitetônico faz parte das primeiras reflexões sobre a preservação da arquitetura moderna, poucas décadas depois de sua inauguração.

Se, a partir dos anos 1980, uma discussão mais aprofundada sobre a produção arquitetônica do movimento moderno foi lançada, ainda na década de 1960 algumas iniciativas passaram a discutir a preservação de obras canônicas da arquitetura moderna, entre elas a Bauhaus. Assim comenta Cláudia Carvalho:

O interesse pela preservação desse legado foi gerado primeiramente pela perda ou desfiguração de importantes ícones do Movimento Moderno, causados não só pelas imposições de adaptação a novas funções, à atualização dos aspectos tecnológicos e ao atendimento a novos padrões de conforto e segurança decorrentes do desenvolvimento econômico e social, mas também pelas rápidas transformações do ambiente construído e as constantes ameaças de demolição.” (CARVALHO, 2006, p. 8) 
No caso da Unidade de Marselha, as fachadas, o terraço e as partes comuns do edifício foram incluídos no inventário dos Monumentos Históricos da França, em 1964. Em 1986, todas as áreas comuns e um dos apartamentos (o de número 643, incluindo o mobiliário original projetado por Charlotte Perriand) foram declarados monumento histórico (NASCIMENTO, 2011).

Em 1995, um segundo apartamento (de número 50) foi inscrito, incluindo também os equipamentos de cozinha. Esse apartamento está preservado com suas peças originais e funciona muitas vezes como espaço de exposições de artistas contemporâneos. Desde 2008, os proprietários do imóvel (Jean-Marc Drut and Patrick Blauwar) abriram suas portas no verão para intervenções artísticas no apartamento. Em 2013, por exemplo, o designer alemão Konstantine Grcic interviu no edifício usando referências do punk rock e uma paleta de cores fortes na tentativa de realizar um diálogo entre a proposta de Le Corbusier e as experiências contemporâneas. Em 2016, a Unidade de Habitação de Marselha - e outras 16 obras de Le Corbusier - foram incluídas na Lista do Patrimônio da Humanidade da Organização das Nações Unidas para a Educação, Ciência e Cultura (Unesco) por refletirem soluções que buscaram solucionar o desafio de uma nova arquitetura que respondesse no século XX às necessidades da sociedade. Ainda segundo a Unesco, essas 17 obras atestam a internacionalização da prática arquitetônica por todo o planeta (UNESCO, 2016).

Os interessados em vivenciar de forma mais intensa o projeto de Le Corbusier podem se hospedar no Hôtel Le Corbusier, que conta com apartamentos para locação, ou alugar um apartamento no através do serviço de hospedagem Airbnb (<http://www.airbnb.com>) - uma busca recente apresentou pelo menos cinco apartamentos disponíveis para aluguel na Unidade de Marselha, sempre ressaltando as qualidades do projeto arquitetônico e a bela vista de Marselha a partir de suas salas.

\section{4 "MÁXIMO CONFORTO E EXCEPCIONAL BELEZA ARQUITETÔNICA"}

Assim como o Esther, outros empreendimentos com áreas maiores e programas diferentes são executados em São Paulo em busca de uma clientela de alto poder executivo, a exemplo do Edifício Eiffel. Projetado 
FIGURA 8

Unidade de

Habitação de

Marselha. Foto:

Flavia Brito do

Nascimento, 2013.

FIGURA 9

Corredor de acesso

às unidades.

Foto: Marina Leonardi, 2013
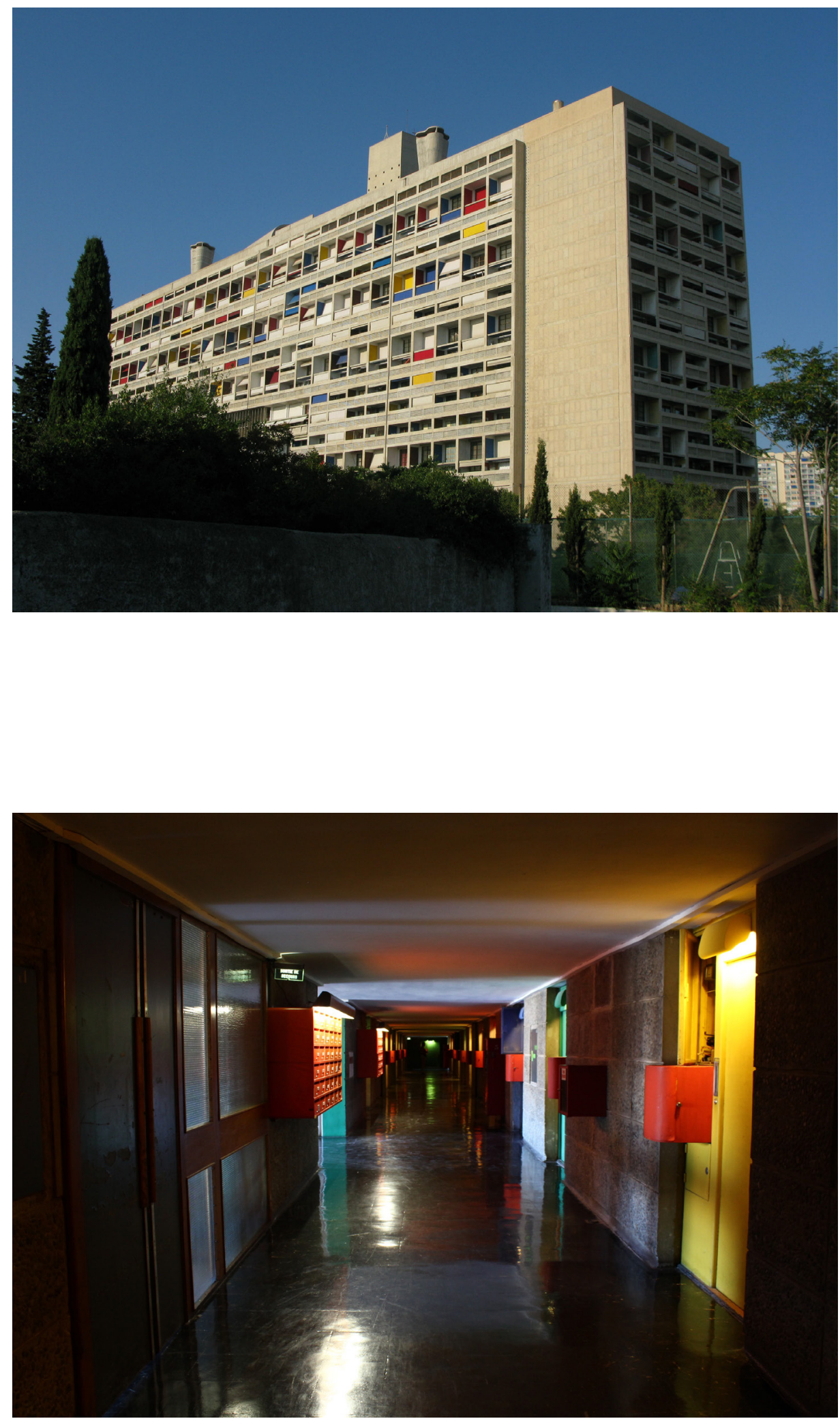
por Oscar Niemeyer, foi um empreendimento da Companhia Nacional de Investimentos (CNI), responsável ainda por outros investimentos imobiliários na cidade e associado à arquitetura moderna. Lançado com interesse em atrair as classes mais ricas, o Edifício Eiffel foi um dos maiores sucessos de venda da Companhia. O anúncio do jornal da época já deixava clara a aceitação da burguesia paulistana à arquitetura moderna:

O clímax residencial de São Paulo - Edifício Eiffel - não há como exigir mais em: (...) Arquitetura: para tão aristocrática localização um grande arquiteto: Oscar Niemeyer. Projetando o Edifício Eiffel, o renomado arquiteto patrício atinge também o clímax de sua arte, uma arte que aqui se traduz numa feliz combinação de funcional distribuição das peças, máximo conforto e excepcional beleza arquitetônica. (Folha da Manhã, caderno Vida Social e Doméstica, p. 4,23, mar. 1952, apud LEAL, 2003, p. 120)

O conjunto arquitetônico reúne 54 apartamentos duplex de dois, três e quatro dormitórios, com áreas muito maiores do que as dos apartamentos duplex dos conjuntos de interesse social. Diferencia-se também pela localização privilegiada e pela "absoluta separação entre partes nobres e de serviço" (SAIA, 1956, p. 135). Os apartamentos duplex do corpo central do edifício apresentam áreas menores do que aquelas das asas laterais do edifício (em geral com quatro dormitórios). Em seu térreo, uma galeria com lojas implantadas em um desenho sinuoso, a exemplo de outras galerias de Oscar Niemeyer.

A organização dos espaços domésticos no Eiffel se diferencia não apenas pela área do apartamento, como também pelo acesso. Ao contrário dos exemplos anteriores, neste exemplar é possível acessar cada célula habitacional pelo pavimento superior, enquanto uma longa escada leva ao pavimento inferior, que reúne os quartos dos moradores. A inversão (áreas sociais acima, áreas íntimas embaixo) é uma tentativa de isolar os sons de cada família em seu próprio domínio, o que parece atestar uma intensa vida social.

As plantas do empreendimento permitem a leitura de diversos aspectos das práticas domésticas sugeridas nesse conjunto habitacional. A sala apresenta grande área livre, onde diferentes setorizações são possíveis (e indicadas nas plantas): jantar, estar e bar. Ali, a vista da Praça da República, emoldurada pelos caixilhos e elementos vazados da fachada, apresenta uma das poucas áreas verdes da região central e a concentração de edifícios na 
FIGURA 10

Edifício Eiffel a partir de um apartamento da torre principal.

Foto: Sabrina

Costa, 2016

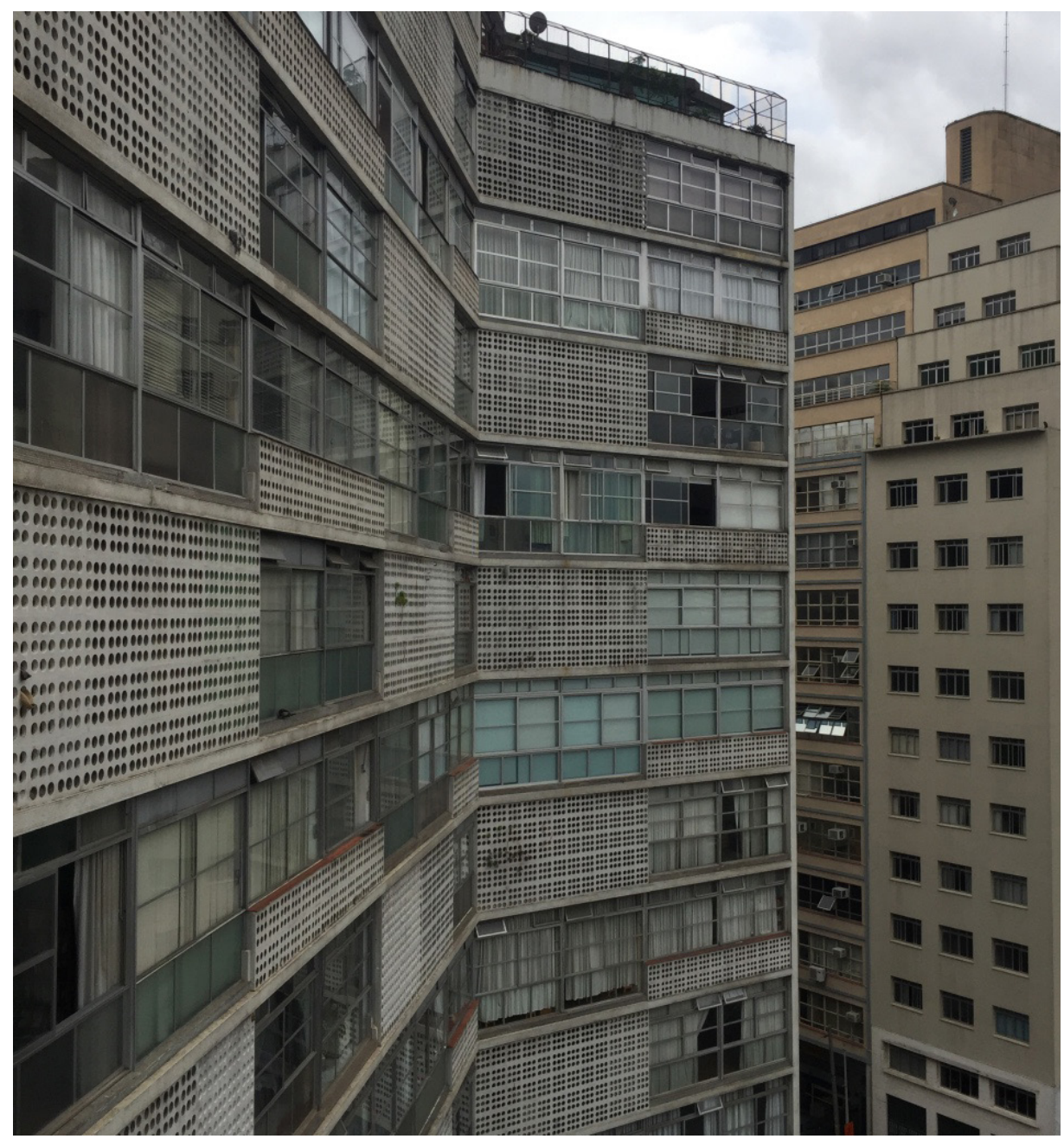

paisagem urbana. Nas áreas de serviço deste pavimento encontra-se uma área para despensa, cozinha e banheiro para os empregados da casa, enquanto no andar inferior os dormitórios amplos voltam-se também para a praça.

Entrevistas com alguns moradores do conjunto residencial apontam que nos últimos dez anos uma nova geração de interessados tem ocupado o prédio. É também comum no Eiffel a presença de arquitetos que, de alguma maneira, acabam por intervir no projeto original e por adaptar o apartamento às demandas da vida contemporânea: cozinhas integradas, estrutura aparente e novos acabamentos internos. 
FIGURA 11

Plantas da torre do edifício Eiffel. Desenhos: Sabrina

Costa e Gabriela Piccinini.

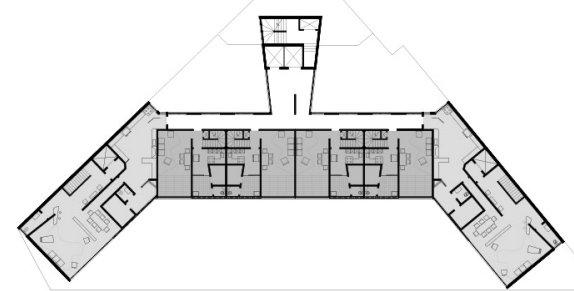

Pavimentos pares (entrada)

\section{EDIFÍCIO EIFFEL}

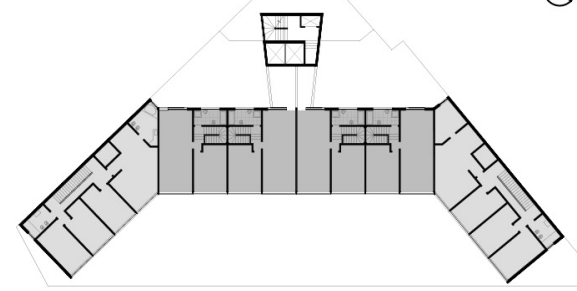

Pavimentos ímpares

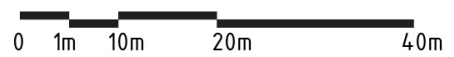

FIGURA 12

Plantas dos

apartamentos

duplex tipos $A$

e $B$ do edifício

Eiffel. Legenda:

vermelho - áreas sociais; azul - áreas

íntimas; amarelo -

serviços. Desenhos:

Sabrina Costa

Gabriela Piccinini.

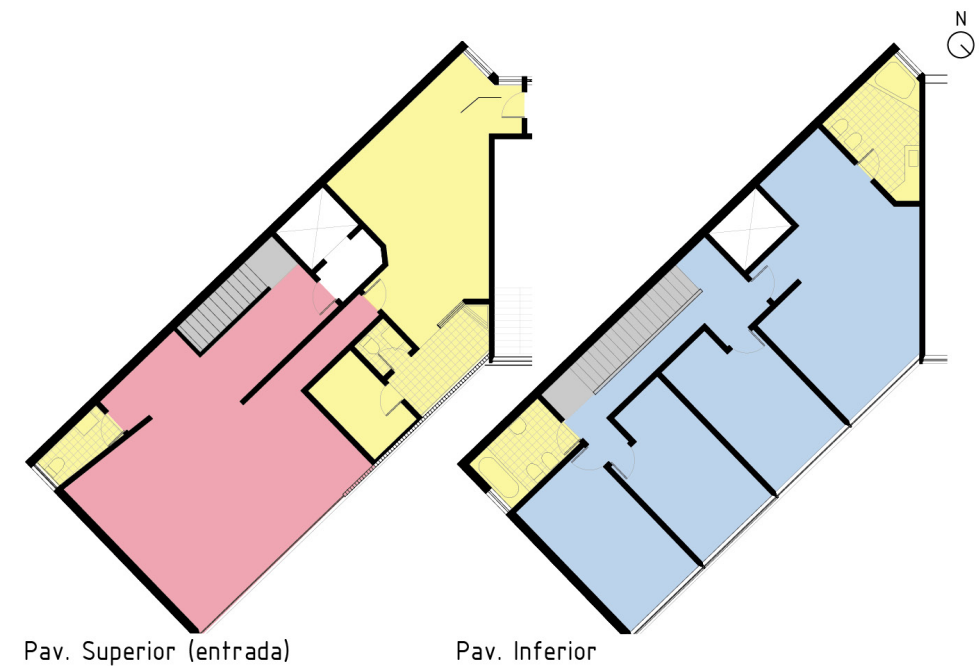

ED. EIFFEL - TIPOLOGIA A
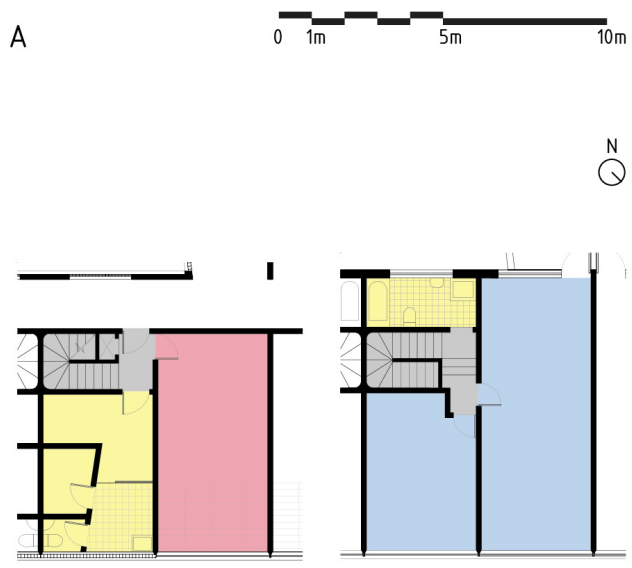

Pav. Superior (entrada)

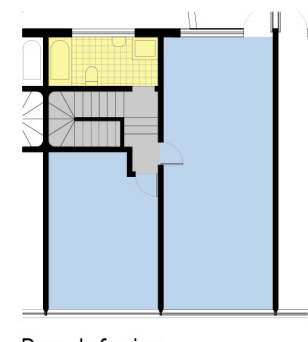

Pav. Inferior

ED. EIFFEL - TIPOLOGIA B

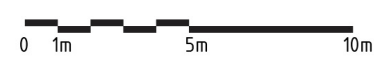


Símbolos do modo de vida moderno, os apartamentos duplex apresentam-se como ícones de despojamento também nas telas do cinema. Somente em 2015, dois filmes nacionais mostraram apartamentos no edifício Eiffel como cenário: Obra, de Gregório Graziosi; e Ponte aérea, dirigido por Julia Rezende. Neste, a protagonista é Amanda, uma jovem publicitária que mora em um apartamento reformado e tem a vista da Praça da República como pano de fundo para diversas cenas que apresentam sua forte figura feminina. Na sala, as festas ocorrem enquanto as luzes do centro da cidade brilham a partir do vidro das esquadrias; no quarto, ao acordar, Amanda olha a janela contemplativa. A fotografia do filme reforça a ousadia da personagem de morar na região central da metrópole.

\section{CONSIDERAÇÕES FINAIS}

Este artigo apresentou um panorama da construção e transformação dos conjuntos habitacionais que ofereceram apartamentos duplex para habitação, buscando compreender os modos de morar propostos em diversos empreendimentos. Se a tipologia se desenvolveu relacionada aos novos modos de morar (especialmente no exemplar soviético, o Narkomfin, onde os espaços íntimos são mínimos e parte das atividades domésticas ocorrem em comunidade e nos equipamentos disponíveis no condomínio), em São Paulo essa tipologia perde o caráter inovador ao ampliar suas áreas e sugerir uma disposição dos cômodos muito próximo ao da casa tradicional.

Demonstra-se aqui que, enquanto as habitações sociais apresentam creches, cozinhas ou lavanderias coletivas e espaços comuns que estimulam uma intensa vida no condomínio - a exemplo do que ocorre no Narkomfin, na Unidade de Marselha e no conjunto Japurá -, nos conjuntos onde os apartamentos têm grandes áreas a vida privada ganha mais intensidade do que aquela que ocorre nas áreas comuns dos condomínios.

É importante ainda ressaltar o desafio que é a gestão de conjuntos habitacionais. Os três exemplos paulistanos estão com as unidades em bom estado de conservação, no entanto, os conjuntos ainda apresentam áreas comuns comprometidas: fachadas, coberturas e acessos precisam de obras de restauro e manutenção. 
Alguns dos conjuntos habitacionais aqui analisados passaram recentemente por processos de valorização de seus apartamentos duplex. Dos cinco empreendimentos analisados, a Unidade de Habitação de Marselha é a que está em melhor estado de conservação e é a única que apresenta reconhecimento internacional. Mesmo inserindo-se no conjunto de obras de Le Corbusier, ganhou o título de Patrimônio da Humanidade pela possibilidade de lançar novos modos de morar. Ali, a vida em comunidade se coloca para os habitantes que reconhecem o valor arquitetônico tanto do complexo habitacional como também de sua própria unidade e da rotina doméstica que ocorre em cada apartamento. As duas unidades habitacionais que são preservadas pela legislação francesa de preservação abrem frequentemente suas portas para lembrar aos interessados (arquitetos, designers, estudantes) que essa proposta doméstica foi lançada em meados do século XX, possibilitando aos visitantes reflexões sobre aquelas ideias e suas variações ao longo do tempo.

\section{REFERÊNCIAS}

ATIQUE, Fernando. Memória moderna: a trajetória do Edifício Esther. 2. ed. São Carlos: RiMa, 2013.

BONDUKI, Nabil. Os pioneiros da habitação social no Brasil. São Paulo: Editora da Unesp, Edições Sesc São Paulo, 2014. v. 1

BONDUKI, Nabil; KOURY, Ana Paula. Os pioneiros da habitação social no Brasil. v. 3. São Paulo: Editora Unesp, Edições Sesc São Paulo, 2014.

CARVALHO, Claudia Sueli Rodrigues. Preservação da arquitetura moderna: edifícios de escritórios no Rio de Janeiro construídos entre 1930-1960. Tese (Doutorado em História da Arquitetura e Fundamentos do Urbanismo) - Faculdade de Arquitetura e Urbanismo, Universidade de São Paulo. São Paulo, 2006.

COHEN, Jean Louis. O futuro da arquitetura desde 1889: uma história mundial. São Paulo: Cosac \& Naify, 2013.

COHEN, Jean Louis; BENTON, Tim. Le Corbusier: le grand. Londres, Nova York: Phaidon, 2008 .

GOODWIN, Philip L. Brazil builds: architecture new and old 1652-1942. Nova York: MoMA, 1943.

KNEESE DE MELLO, Eduardo. Apartamentos para industriários. IAPI delegacia de São Paulo. Rua Japurá - São Paulo. Acrópole, São Paulo, n. 119, p. 281-287, 1948.

KOPP, Anatole. Quando o moderno não era estilo e sim uma causa. São Paulo: Nobel, Edusp, 1990. 
LEAL, Daniela Viana. Oscar Niemeyer e o mercado imobiliário de São Paulo na década de 1950: o escritório satélite sob a direção do arquiteto Carlos Lemos e os edifícios encomendados pelo Banco Nacional Imobiliário. Dissertação (Mestrado em História da Arte) - Instituto de Filosofia e Ciências Humanas, Universidade Estadual de Campinas. Campinas, 2003.

MALUF, Marina e MOTT, Maria Lúcia. Recônditos do mundo feminino. In: SEVCENKO, Nicolau (org.) Da belle époque à era do rádio: história da vida privada no Brasil. São Paulo: Companhia das Letras, 1998. v. 3

MARINS, Paulo César Garcez. Habitação e vizinhança: limites de privacidade no surgimento das metrópoles brasileiras. In: SEVCENKO, Nicolau (org.) Da belle époque à era do rádio: história da vida privada no Brasil. São Paulo: Companhia das Letras, 1998. v. 3

NASCIMENTO, Flavia Brito. Blocos de memórias: habitação social, arquitetura moderna e patrimônio cultural. Tese (Doutorado em Habitat). Faculdade de Arquitetura e Urbanismo, Universidade de São Paulo, São Paulo, 2011.

RANN, Jamie. Narkomfin: can a utopian housing project survive in modern Moscow? The Calvert Journal. Moscou, 2014. Disponível em: <http://calvertjournal.com/comment/ show/2294/narkomfin-moscow-constructivism-renovation>. Acesso em: 22 set. 2016.

REGINO, A. N.; PERRONE, R. A. C.. Eduardo Augusto Kneese de Mello: sua contribuição para habitação coletiva em São Paulo. Risco Revista de Pesquisa em Arquitetura e Urbanismo, São Carlos, n. 9, p. 56-97, 2009.

SAIA, Luís. Notas sobre a evolução da morada paulista. Revista Acrópole, n. 208, p. 131-135, jan. 1956.

UNESCO. The architectural work of Le Corbusier, an outstanding contribution to the Modern Movement. Disponível em: <http://whc.unesco.org/en/list/1321>. Acesso em: 7 set. 2016.

VILLA, Simone Barbosa. Apartamento metropolitano: Habitações e modos de vida na cidade de São Paulo. Dissertação (Mestrado em Arquitetura e Urbanismo) - Escola de Engenharia de São Carlos, Universidade de São Paulo. São Carlos, 2002. 